\title{
Terrestrial Laser Scanning for Plot-Scale Forest Measurement
}

\author{
Glenn J. Newnham ${ }^{1,9} \cdot$ John D. Armston ${ }^{2,3,9} \cdot$ Kim Calders ${ }^{4,5,9}$ • Mathias I. Disney ${ }^{5,9,10}$ • \\ Jenny L. Lovell ${ }^{1}$ - Crystal B. Schaaf ${ }^{6,9}$ • Alan H. Strahler ${ }^{7,9}$ • F. Mark Danson ${ }^{8,9}$
}

Published online: 27 October 2015

(C) Springer International Publishing AG 2015

\begin{abstract}
Plot-scale measurements have been the foundation for forest surveys and reporting for over 200 years. Through recent integration with airborne and satellite remote sensing, manual measurements of vegetation structure at the plot scale are now the basis for landscape, continental and international mapping of our forest resources. The use of terrestrial laser scanning (TLS) for plot-scale measurement was first demonstrated over a decade ago, with the intimation that these instruments could replace manual measurement methods. This has not yet been the case, despite the unparalleled structural information that TLS can capture. For TLS to reach its full potential, these instruments cannot be viewed as a logical progression of existing plot-based measurement. TLS must be viewed as a disruptive technology that requires a rethink of vegetation surveys and their application across a wide range of disciplines. We review the development of TLS as a plotscale measurement tool, including the evolution of both instrument hardware and key data processing methodologies. We highlight two broad data modelling approaches of gap probability and geometrical modelling and the basic theory
\end{abstract}

This article is part of the Topical Collection on Remote Sensing

Glenn J. Newnham

Glenn.Newnham@csiro.au

1 Commonwealth Scientific and Industrial Research Organisation, Private Bag 10, Clayton South, VIC 3169, Australia

2 Queensland Government Department of Science, Information Technology and Innovation, Queensland, Australia

3 Joint Remote Sensing Research Program, University of Queensland, Queensland, Australia

4 National Physical Laboratory, Twickenham, UK

5 Department of Geography, University College London, London, UK that underpins these. Finally, we discuss the future prospects for increasing the utilisation of TLS for plot-scale forest assessment and forest monitoring.

Keywords Forest plot measurement · Terrestrial laser scanning $\cdot$ Vegetation measurement

\section{Introduction}

\section{Forest Plot Measurement}

Plot-scale forest measurements have been the basis for commercial forest inventory since the late eighteenth century [1]. With increasing recognition of multiple benefits of forest ecosystems, environmental and ecologically focussed forest surveys [2] have gradually expanded into national $[3,4]$ and international $[5,6]$ reporting strategies. These include long-term (multi-decadal) forest plot networks used to study forest dynamics in response to drivers such as

6 School for the Environment, University of Massachusetts Boston, Boston, USA

7 Department of Geography and Environment, Boston University, Boston, USA

8 School of Environment and Life Sciences, University of Salford, Salford, UK

9 Terrestrial Laser Scanner International Interest Group (TLSIIG), Wokingham, UK

10 NERC National Centre for Earth Observation (NCEO), Wokingham, UK 
climate change [7]. In such cases, the forest plot forms the basic sampling unit from which various inferences are made and reported.

The measurements recorded at the forest plot level depend on the objective of the survey. Traditionally, these measurements have been limited by the measurement methods available or the efficiency with which the measurement can be taken. The Biltmore stick [8] is one early example of an angle-based measurement of both diameter at breast height (DBH) and tree height for the purpose of determining timber volume. However, characterising stem number density $(\psi)$ has also been important for scaling up single tree volumes to stand-level estimates. From these variables, basal area (BA) can be derived:

$B A=\frac{\pi \psi}{4} \overline{D B H^{2}}$

Where mean DBH is measured in metres and $\psi$ is measured in stems per metres squared. This continues to be the primary measure from which forest timber resources are evaluated. Efficient ways to characterise BA were introduced in the mid-twentieth century [9•], which involved the use of socalled plotless sampling, but they have also been called variable radius plots $[10,11]$. With improvements in the timber production and processing chains, more detailed characterisation of stem form has become important, such as stem taper, sweep and branching characteristics. These aspects of stem form are often summarised as a form factor $(\mathrm{FF})$, which gives the relationship between the true volume of a tree and the volume of a cylinder of base area $B A$ and length $h$. The FF can vary with species and tree age and due to environmental conditions and is usually determined via destructive measurements [1]. The basic equation for assessing timber volume at the plot scale then has the general form

$$
V=B A \times h \times F F
$$

This equation is still in common use in commercial forestry and is an example of an isometric scaling equation, where the volume is proportional to the cube of its linear dimensions. In contrast, recent applications of plot-based measurement to assess the aboveground biomass (AGB), equivalent to the tree volume multiplied by some density function $\rho$, use allometric equations [12] using the exponential form

$A G B=\rho V=\exp \left(\beta_{0}+\beta_{1} \ln (D B H)\right)$

where $\beta_{0}$ and $\beta_{1}$ are empirically derived parameters. A wide range of these allometric relationships have been developed and applied. However, they are often based on small samples of trees, resulting in unknown uncertainty when applied outside their calibration range. Recent studies have attempted to develop generic allometric equations using data collated from multiple studies $[13,14]$.
Increasing recognition of diverse forest values, such as AGB, have broadened the type of measurements that are considered important. Critical among these measurements is quantifying forest canopy gap fraction, specifically the proportion and size distribution of within- and between-crown gaps when observed from the forest floor. This is important for understanding the canopy radiation regime and can be used to determine leaf area index $(L)$, defined as the onesided leaf area per unit ground area [15]. Leaf area is an important biophysical measure, as it is the area where a plant's energy and water exchange occurs. Although the association between gap fraction and $L$ requires a range of assumptions, it is very efficient when compared to destructive measurements that are generally prohibitively time-consuming.

MacArthur and Horn [16*] extended the value of gap fraction measurements by determining the distance to the intersection of plant components using a camera with a range calibrated focal ring. This allowed the derivation of what they termed "foliage profiles" describing the vertical distribution of the leaf area, which is a key to understanding natural succession and recovery after disturbance.

Whether forest surveys have a commercial or environmental focus, the common aspect of these measurements is that they broadly capture and quantify forest structure. From structure, we infer variations in site productivity, radiation regime (reflectance and absorption) and standing biomass. From changes in structure, we can infer inter alia disturbance, recovery, succession and growth.

Plot-based forest measurements are of relatively limited value unless they can be scaled up (extrapolated) to the landscape scale. Traditionally, this was performed using a method known as timber cruising $[17,18]$. Here a forester walks transects through the forest and makes rapid measurements such as variable radius BA. The relationship between cruising assessments and accurate measurements within intensively measured plots can be used to remove bias. Timber cruising is rapidly being replaced by remote sensing methods for scaling up plot-based surveys. Early applications of aerial photography have gradually given way to the use of more sophisticated aerial and satellite imagery. Empirical relationships between such measurements and the forest metric of interest (e.g. harvestable timer volumes and AGB) are then used to map the metric over the landscape.

In the past decade, there has been a growing interest in terrestrial laser scanning (TLS) as a tool for forest plot measurement. However, since the first demonstrations for forest measurement over a decade ago [19••, 20], there has been relatively little uptake of the technology for routine and operational forest assessment. This is despite many of the traditional forest structural measurements being captured within the three-dimensional datasets recorded by these instruments. In fact, the characterisation of forest structure is far more detailed within a TLS scan than any measurements recorded in 
traditional forestry and ecological surveys, or directly from airborne or satellite remote sensing measurements. The focus for the past decade has been how best to simplify these TLS data down to the more basic structural metrics that are historically accepted for plot-based assessment and reporting.

TLS is not a development in forest measurement tools, it is a disruptive technology that requires rethinking of the way that forest measurement is done. In essence, TLS presents an opportunity to go beyond simple empirical isometric and allometric equations to the point where three-dimensional measurements of vegetation structure are utilised as a basis for assessing volume, monitoring growth and assessing disturbance. In the same way, TLS will allow us to go beyond tenuous empirical relationships between measurements of plot-based structure and airborne and satellite imagery, to a point where we can directly scale up ground-based measurement of structure such as foliage profiles with like measurements recorded from airborne lidar, and develop 3D models that can be used to test and benchmark remote sensing instruments and canopy radiative transfer models.

\section{Evolution of TLS for Vegetation Measurement}

The development of terrestrial laser scanners has lagged behind the development of airborne systems [21], which were used for forest measurement from the mid-1980s [22]. Some of the first commercial TLS instruments appeared in the late 1990s with examples like the RIEGL LMS Z210 [23] and CYRAX 2200 [24]. These instruments were based on the time-of-flight ranging principle and employ a pulsed laser with pulse length of the order of $5 \mathrm{~ns}$. Reflected pulses are detected by the system and the time of flight is recorded, according to some pre-determined algorithm. Such algorithms include determining the time of the return pulse peak intensity, pulse leading edge and pulse centre of gravity, among others [25•]. Given the time triggered for a return $(t)$, the range $(r)$ to the target is given by

$r=\frac{c t}{2}$

where $c$ is the speed of light. Scanners employing phase-shift ranging followed soon after, including scanners from IQSun (later to be bought by the German FARO company), Zoller+ Frohlich IMAGER 5003 and the Leica HDS 4500 systems [26]. The phase shift principle uses intensity (I) modulation of a constant wave laser. The phase of any reflected signal is measured to determine the range according to the equation

$r=\frac{\Delta \varphi \lambda}{4 \pi}+\frac{\lambda}{2 n}$

where $\lambda$ is the wavelength of intensity modulation and $n$ is an unknown number of whole wavelengths. An inability to resolve $n$ imposes a limitation on the range of phase-shift instruments to $\lambda / 2$ [21] or $\lambda$ if $\delta I / \delta t$ is known, while the accuracy with which a range can be determined is inversely proportional to $\lambda$. These incompatible requirements are overcome by superimposing multiple intensity modulation wavelengths onto the same constant beam. For example, the Faro LS $880 \mathrm{HE} 80$ is quoted as having modulation wavelengths of 1.2, 9.6 and $76.8 \mathrm{~m}$ giving it an unambiguous range of $>70 \mathrm{~m}$ [27], since $\delta I / \delta t$ is difficult to determine as $I$ approaches zero.

Some of the early time-of-flight TLS instruments, such as the CYRAX 2200 and Optech ILRIS 3D, had quite restricted scanning fields of view, indicative of their built environment focus. Both the CYRAX 2200 and Optech ILRIS 3D instruments scanned a window of $40^{\circ}$ in zenith and azimuth. The emergence of phase-shift technologies also saw a number of first fullhemispherical scanning instruments. The IQSun, Zoller+ Frohlich and the Leica HDS instruments all allowed full $360^{\circ}$ azimuth and $320^{\circ}$ zenith scanning, providing the ability to scan an entire (variable radius) plot from a single location.

In parallel to developments in phase-shift scanning, development of an instrument specifically targeting forest measurement was underway. The Echidna Validation Instrument, or EVI [19••, 28••, 29••], utilised full-hemispherical full-waveform recording rather than discrete range detection. In this case, a pulsed laser is used and all reflected energy returning to the instrument is digitised. The full-waveform recording approach of the EVI borrows heavily from lidar systems used for atmospheric profiling [30] in recognition of the fact that tree canopies are made up of leaves with variable spatial distributions and orientations within an irregular crown envelope. Like atmospheric profiling, multiple intersections of the beam are common within tree crowns. Jupp et al. [29••] describe a model for the laser waveform intensity as a function of $r$ using the equation

$I(r)=\Phi_{0} * \frac{K(r) \rho_{\mathrm{t}}(r)}{r^{2}}$

where $\Phi_{0}$ is the outgoing pulse intensity, $K(r)$ is an instrumentspecific detector efficiency factor [31] and $\rho_{\mathrm{t}}$ is the reflectance of targets intercepted by the beam at any range $r$ along the outgoing beam path. Given the finite width of a laser pulse, the * symbol represents the convolution of the outgoing pulse intensities with the discrete ranges at which they are intercepted. It can be seen that the expected return intensities for a target with given reflectance will vary depending on the target range, which may complicate the identification of targets in the presence of instrument noise. While object detection may be based on non-range-dependent methods as described by Jutzi and Stilla [25•], this model can be used to determine appropriate range-dependent thresholds for a given target reflectance and instrument signal-to-noise ratio. Given a detected return pulse, there are a number of methods that can 
be used to determine the target range, which have been summarised by Jutzi and Stilla [25•].

The interpretation of a waveform $I(r)$ in terms of target properties is based on the inversion of this equation to determine what is known as apparent reflectance $\rho_{\text {app }}$ :

$\rho_{\text {app }}(r)=\frac{I(r) r^{2}}{K(r) \Phi_{0}}$

which represents the reflectance of a diffuse target that is normal to the beam direction and completely fills the beam at range $r$. This is an inherent property of the target, which accounts for characteristics for the instrument $\left(I, K, \Phi_{0}\right)$ and measurement $(r)$ characteristics.

Waveform recording instruments have been commercialised by the Austrian company RIEGL, including the RIEGL VZ400 and VZ1000. These systems have a finer scan resolution than the EVI due to their precision surveying heritage. However, they record only samples of the full waveform that correspond to returns detected using proprietary onboard waveform processing algorithms.

Recently, two vegetation lidar systems have carried on the full-waveform recording approach of the EVI, with the added feature of dual-wavelength scanning. The Salford Advanced Laser Canopy Analyser, or SALCA [32, 33••], and the Dual Waveform Echidna Lidar, or DWEL [34••], use two laser wavelengths, 1064 and $1545 \mathrm{~nm}$ for the SALCA, and 1064 and 1548 for the DWEL. This is intended to allow separation of moist photosynthetic components from woody material (e.g. Fig. 1) or the direct evaluation of moisture content [35]. This approach is designed to allow the use of specific methods for independent modelling of woody structures and the distribution of leaf area.

\section{Modelling Approaches}

Just as TLS instruments initially designed for built environment surveys have developed to become more readily applicable to the specific requirements of vegetation measurement, methods for TLS data analysis have also been adapted from other disciplines. Jupp et al. [29••] refers to a forest as being made up of two broad component categories, hard and soft targets. Essentially, they draw a distinction between woody objects where the angular sampling and beam divergence mean that multiple complete interceptions of the beam are likely. This contrasts with canopy objects (leaves and needles) that are small and have variable orientations and distributions in space. These soft targets result in a higher proportion of multiple partial interceptions of a single beam. The distinction between hard and soft targets transfers to the processing approaches that have been applied in the literature. Some draw on built environment three-dimensional modelling and others draw from more statistical treatment with origins in atmospheric profiling.

\section{Gap Probability}

Gap within the forest can be considered the complement of the volume of all vegetation components. The measurement of gap has been used for many years for determining forest structure such as $L$ and $B A$. The measurement of $L$ is based on multi-angular gap probability theory [36]. In the case of randomly distributed leaves in the horizontal plane

$L=\frac{-\ln \left(P_{\text {gap }}(\theta)\right) \cos \theta}{G(\theta)}$

where $P_{\text {gap }}(\theta)$ is the gap probability at any zenith angle $\theta$, often measured by thresholding the brightness values in upward looking hemispherical photography. $G(\theta)$ is the Ross [37] function to describe the probability distribution for the projection of the leaf area in the direction $\theta$. Depending on the nature of the $G$ function, $L$ is estimated using linear [29.•] or non-linear [38] least squares.

Early examples of ground-based laser systems include the Decagon Devices Leaf Laser [39]. This was used to determine leaf area index based on multi-angular gap probability theory [36]. However, the system was never made commercially available [40] and was said to have been limited by its effective range of $10 \mathrm{~m}$. Other early examples of non-scanning laser systems were used to measure foliage profiles based on walking a transect with zenith pointing conventional range finders [40]. Lovell et al. [19••] provide one of the first examples of the application of a simple hemispherical TLS instrument, the Rangefinder Prototype Echidna (RPE), which was used to measure foliage profiles. The results of their work were also used to compare ground-based measurements of foliage profiles to those derived from airborne laser scanning data.

The basis for the foliage profile measurement used by Lovell et al. [19••] marries the multi-angular gap probability theory with the vertical gap probability theory demonstrated by MacArthur and Horn [16•]. From the perspective of discrete return TLS, the gap probability of a horizontal layer of the forest from the ground to some height $z$ can be approximated by

$P_{\text {gap }}(z, \theta)=1-\frac{\# r \mid r \cos \theta<z}{N(\theta)}=\frac{\# r \mid r \cos \theta \geq z}{N(\theta)}$

where the numerator is the number of range measurement $(\# r)$ in the zenith angle increment $\theta$ that falls below the level $z$. The denominator $N$ is the total number of laser shots for the zenith angle increment $\theta$. In the case of a waveform instrument and assuming Lambertian reflectance, $P_{\text {gap }}$ is approximated using the integral of $\rho_{\text {app }}$ as follows 


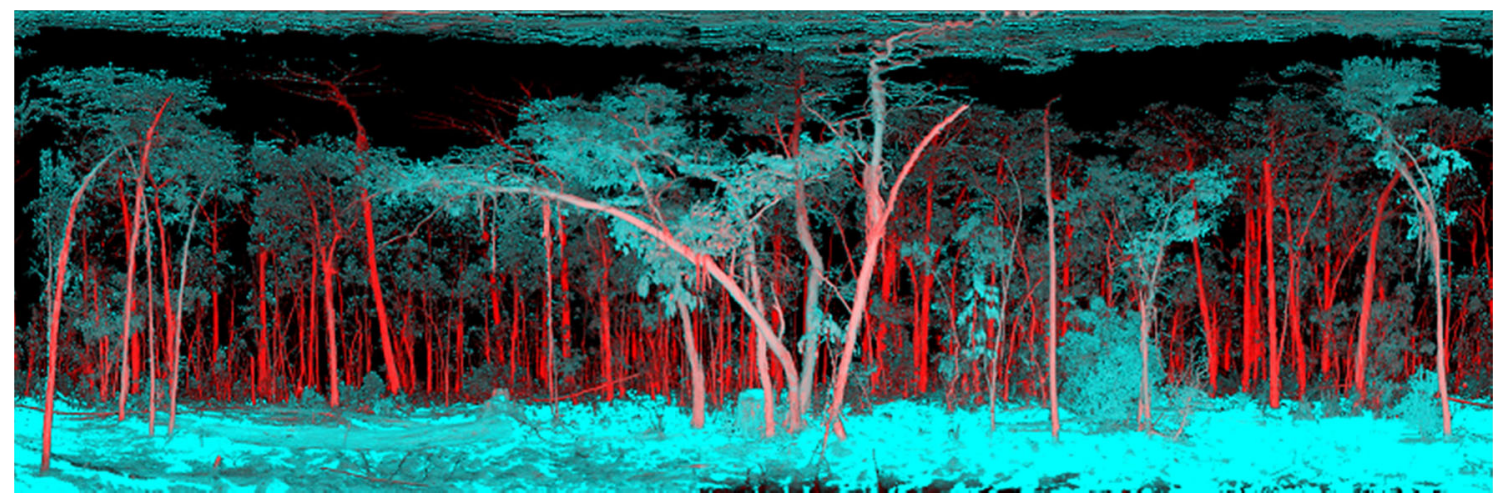

Fig. 1 Dual-wavelength Echidna lidar (DWEL) scan of an open eucalyptus forest at Tumbarumba, Australia. The image uses a blue-red colour table applied to the normalised difference index (NDI), which uses

$P_{\text {gap }}(\mathrm{z}, \theta)=1-\frac{\int_{0}^{z=r \cos \theta} \rho_{\text {app }}(r) d r}{\rho_{\mathrm{a}} G(\theta)^{2}}$

where $\rho_{\mathrm{a}}$ is the normal reflectance of the target. An assumption of the appropriate $\mathrm{G}$ function and some scaling of $P_{\text {gap }}$ are generally applied $[29 \bullet \bullet]$. At the base of the canopy $z=0$, no canopy elements have been detected by the TLS instrument so $P_{\text {gap }}=1$. At the top of the canopy $z=h$, in theory, all elements that are within the field of view have been detected and

$P_{\text {gap }}(h, \theta)=e^{-\mathrm{G}(\theta) \mathrm{L} / \cos \theta}$

Thus, $P_{\text {gap }}(z, \theta)$ is a monotonically decreasing function with increasing height, which leads to a monotonically increasing function describing the cumulative leaf area:

$L(z)=\frac{-\ln \left(P_{\text {gap }}(z, \theta)\right) \cos \theta}{G(\theta)}$

The foliage profile is simply the derivative of this cumulative leaf area:

$f(z)=d L(z) / d z$

Foliage profiles derived from TLS have been published by many authors since those demonstrated by Lovell et al. [19••]. Their value over and above the estimation of $L$ is clear, since they include information on canopy height and relative areal density of canopy elements within strata (e.g. Fig. 2). Work continues to improve the retrieval of these profiles by addressing issues of canopy clumping [41], to address influence of topography [42] and to test new instrument types [43].

The measurement of gap can also be used to determine the woody structure within a forest. Assuming a random distribution of tree stems and no occlusion by undergrowth and branches, Lovell et al. [44] describes the gap probability for a forest in the horizontal plane at breast height as the wavelength combination $(1064-1548) /(1064+1548)$. The distinction between woody and non-woody material can clearly be seen in the level of the NDI irrespective of range from the instrument

$P_{\text {gap }}\left(r, \theta=\frac{\pi}{2}\right)=e^{-\psi \overline{D B H} r}=e^{-2 \sqrt{\frac{\psi B A}{\pi}} r}$

This measurement of gap is a useful structural metric in itself, although it is a function of traditional metrics. To determine $\psi, \mathrm{DBH}$ or $\mathrm{BA}, \mathrm{DBH}$ can first be estimated from unoccluded trees. Once DBH is known, $\psi$ and then BA can be determined from measured $P_{\text {gap }}$. Conversely, $\psi$ can be estimated based on the expected number of unoccluded trees as a function of $r$, allowing DBH or BA to be computed.

Both Strahler et al. [28••] and Lovell et al. [44] describe the use of TLS to replicate Bitterlich [9] angle count methods to estimate BA directly. In the case of [44], the intensity as the beam traverses a stem along the horizontal plane was used to determine angular span. Yao et al. [45] used these methods and existing allometric equations to determine stand biomass, explaining $85 \%$ of the variance in those derived from field survey methods.

Assessment of BA using TLS is of limited use if estimates cannot be extrapolated over the landscape. One of the key values of the foliage profile $f(z)$ is the fact that it provides a direct link to airborne lidar surveys. In theory, the vertically projected foliage profile is equivalent to those derived from airborne lidar $[19 \bullet \bullet, 46,47]$. This provides a unique way to scale up the detailed multi-angular assessments from TLS [48•]. For example, if the form factor for a given forest type is known and height can be measured directly using airborne lidar data, isometric or allometric relationships between $f(z)$ and BA can be used to map timber volume at compartment or landscape scales (Eq. 2).

\section{Geometrical Modelling}

In parallel to the development of $P_{\text {gap }}$ methods for assessing forest structure, methods were also being developed that attempt to model the geometrical structure of forest objects. Geometrical modelling approaches exploit the structure of 
Pre-burn (2012-12-18)

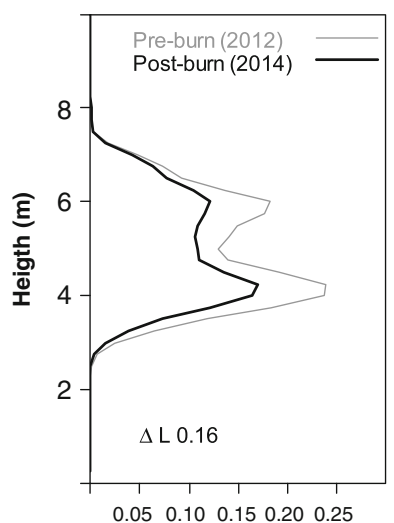

$\mathrm{f}(\mathbf{z})$

Fig. 2 Example TLS foliage profiles, $f(z)$, and hemispherical apparent reflectance, $\rho_{\text {app }}$, images showing canopy change $(\Delta L=0.16)$ in a eucalypt-dominated mallee low open woodland at Calperum-Chowilla, South Australia. A fire on 17th January, 2014 caused an estimated $38 \%$

discrete point clouds obtained from TLS. These initially tended to focus on characterising woody components (Jupp et al. [29••] refers to these as hard targets) but have gradually progressed towards being able to model the whole tree, including foliage.

An early example is that of Aschoff and Spiecker [49] who used point clouds generated using the Zoller+Frohlich IMAGER 5003 to determine stem diameters at 1.3 and $7 \mathrm{~m}$, which are critical heights for determining form factor and volume. Unlike Strahler et al. [28••] and Lovell et al. [44], Aschoff and Spiecker [49] determined these diameters via circle fitting rather than angular span. This can be done via linear least squares, noting that for a set of $N$ coordinates $\left\{\left(x_{\mathrm{i}}\right.\right.$, $\left.\left.y_{\mathrm{i}}\right) \mid 0 \leq i<N\right\}$, the circle with centre coordinates $\left(x_{0}, y_{0}\right)$ and radius $r$ is obtained by minimising the sum of $\varepsilon_{\mathrm{i}}^{2}$ in the linear set of equations:

$x_{\mathrm{i}}^{2}-y_{\mathrm{i}}^{2}=2 x_{\mathrm{i}} x_{0}+2 y_{\mathrm{i}} y_{0}+r-x_{0}^{2}-y_{0}^{2}+\varepsilon_{\mathrm{i}}$

In the simple single-scan case, this equation is fitted to the arc of points recorded on the scanner side of the stem. The key here is the segmentation of points on a single stem within a given height increment. Generally, this is achieved using clustering and filtering algorithms. For example, a structure element is centred over each point, and it is rejected as a stem point if there are less than $n$ points found within the structure element region. The approach was extended to model the taper of tree stems, which formed the basis for the TreeMetrics AutoStem(TM) software [50]. The circular Hough transformation has also been used for the detection and the estimation of DBH [51], where possible circles are scored on the basis of their likelihood given the location of points in the horizontal plane. More rigorous approaches utilise the full threedimensional location of points using cylinder modelling [52,

\section{Post-burn (2014-03-05)}

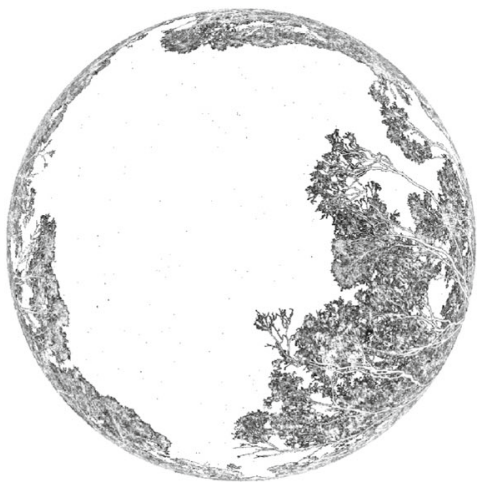

loss of observed canopy foliage, while the woody structure remained largely intact. The TLS data was collected using a RIEGL VZ-400 (laser wavelength $1550 \mathrm{~nm})$. The $f(z)$ estimates were generated following the procedures in [42]

53], although this requires an iterative solution, as opposed to the linear expression for circle fitting.

Clearly, the best geometrical model for an object is one that is created from a point cloud where there is no occlusion. Since conventional TLS is recorded from a fixed point, occlusion is inherent in the scan. One of the challenges for geometrical modelling is to determine the minimum number of scans required to achieve a reasonable model of the tree, plot or area of interest. Some authors refer to this as (single or multiple) scan mode [54, 55].

The use of multiple-scan modes brings with it the challenge of precise and automated merging of scans into a single point cloud. The built environment approach uses highly reflective targets observable from multiple scan locations to use as tie points for such a merge [56]. This has been applied successfully in forest and ecological applications [57, 58••, 59]. However, targets can be difficult to position within a dense forest so that they are unoccluded within multiple scans, due to the many trees within the plot. Some consider the use of targets in forest surveys impractical [60], while others contend that technological improvements in TLS range and precision mitigate some of these impracticalities [61]. Yang et al. [62] used manual manipulation to align scans for reconstruction of a forest scene, while other authors have used stem centroids as tie points for merging scans [60].

Hosoi et al. [63] used voxelisation of the point cloud $\left(0.5 \mathrm{~cm}^{3}\right)$ to define the surface area of trees within a point cloud, while Beland et al. [64] used a similar approach to estimate $L$ while accounting for occlusion. These voxelbased approaches do not constrain the model to a specified shape but do require objects of interest to be delimited within the point cloud. Work by Dassot et al. [65] showed that it was possible to model trees using point cloud meshing within software designed for engineering surveys. They modelled stem 
and branch diameters as cylinders down to a minimum diameter of $7 \mathrm{~cm}$. The estimated timber volumes were within $10 \%$ of harvested volumes, but the cylinder modelling process required significant manual input.

Côté et al. [66] developed a method to reconstruct whole tree architecture by separating woody and foliage components based on the intensity of TLS returns. The woody skeleton of the tree is then modelled using the high-intensity points. A free-form circular cross-section woody model is then built around this skeleton. Fine branching structure and foliage are then added to the woody structure based on the lowintensity points. This model was further refined and described as the L-Architect model in Côté et al. [67]. The addition of leaves is such that the whole tree model respects the gap probability from the perspective of the TLS instrument location, albeit averaged over the within-crown volume.

Raumonen et. al [68・*] presented a reconstruction method for precision tree models from TLS point clouds (Figure 3).

The resulting quantitative structure model (QSM) is based on cylinders and provides direct information about branch size distributions and volume. Calders et al. [58・•] compared estimates of AGB from these QSMs and tree basic density with estimates from destructive harvesting. Results showed an overestimation of $9.7 \%$ for the TLS QSM method compared to a $29.9 \%$ underestimation when traditional allometric equations were used. This suggests that estimates of AGB from TLS do not require allometric equations and have well-characterised uncertainty that is independent of tree size. Hackenberg et al. [69] present a similar approach showing accurate AGB estimation in orchard systems using phased-based TLS data. Liski et al. [70] also applied an extension of the QSM modelling approach, including a polyhedral mesh, to generate stump-root system models for estimation of carbon dioxide emissions from harvest residue, showing that it is possible to model even more complex geometries than trunk and branch structures.

\section{Future Directions}

Although there has been significant development in the methods used to assess forest plots using TLS, the challenges of balancing survey efficiency with measurement detail and accuracy remain. Although very detailed single tree models can be produced $[68 \bullet \cdot, 70]$, these are generally attained through carefully merged scans and are likely to be more time-consuming to apply at the plot scale. The use of gap probability and variable radius plots to characterise forests requires only a single scan, which remains very attractive for forest mensuration and large-area sampling, but the resulting metrics are often indirectly related to the feature of interest and hence conceptually difficult to accept for those accustomed to traditional forest surveys. Future developments in both hardware and data processing methods will help to create synergies from both approaches. However, specific applications require quite different information from plot-based forest surveys, and these will also dictate the path of hardware and software development.

\section{Instrumentation}

The body of research cited here has shown that TLS can be used to record and measure forest structure. However, broader acceptance of TLS as a valid alternative to manual survey methods requires efficient and affordable hardware. A number of examples of low-weight $(<5 \mathrm{~kg})$ low-cost $(<\mathrm{USD} \$ 20,000)$ instruments have been reported recently in the literature. From
Fig. 3 Example of a point cloud coloured by height (left) and the derived quantitative structure model (QSM) (right) for a 21-mtall Eucalyptus tricarpa in Rushworth forest, Australia. The TLS data was collected using a RIEGL VZ-400, and the QSM was generated following the procedure described by Calders et al. $[58 \bullet \bullet]$
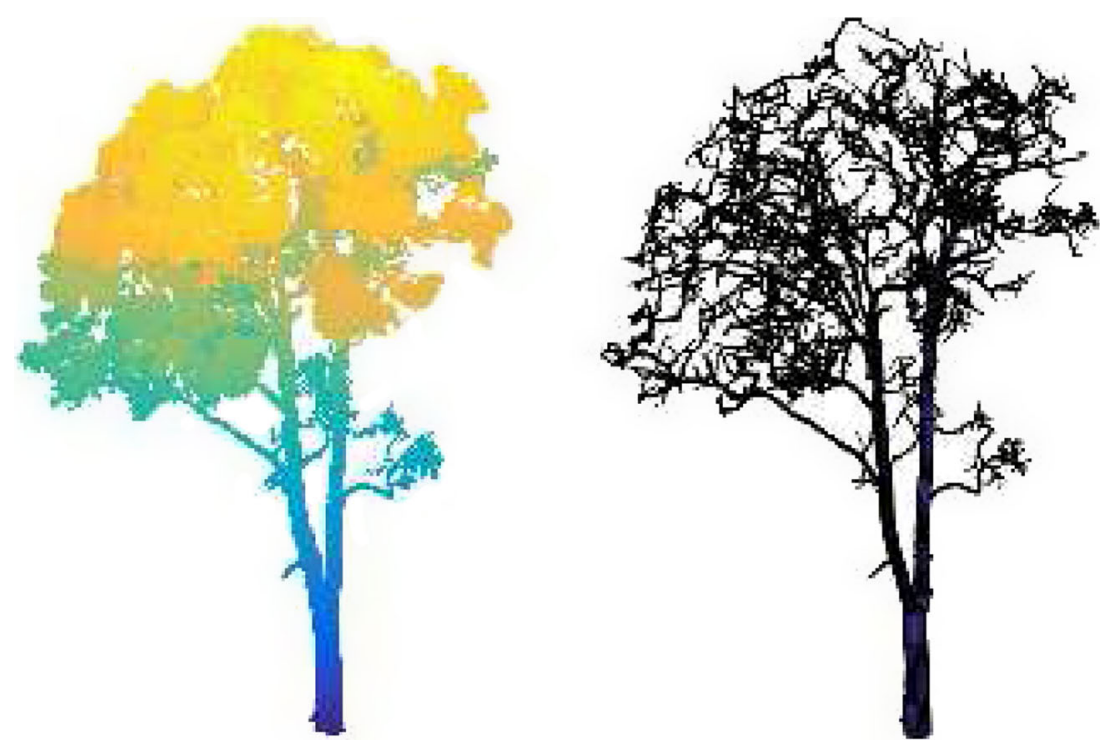
a conventional hemispherical scanning perspective, Kelbe et al. [71] have shown that it is possible to produce a highly portable instrument by mounting a low-cost lightweight timeof-flight scanner on a simple rotary table and produce estimates of stem diameter and form. Schaaf et al. have refined this design and tested the system for measuring structure and biomass in challenging environments such as tropical forest, mangroves and salt marshes $[72,73]$. There are also examples of permanently deployed TLS instruments designed to monitor forest structural change over time $[74,75]$ and linking time series of structural measurements to ecological drivers [76 $\left.{ }^{\bullet}\right]$. While these instruments give up some performance in terms of maximum range, angular resolution and positional accuracy, they can be a useful tool for gap probability-based characterisation of forest plots. These research instruments also demonstrate a need that is likely to become a focus for commercial instrument development in the future.

In contrast to these low-cost instruments, the development of high-performance instruments that incorporate new features is likely to gain pace. Commercial waveform recording instruments are now available, and we have already seen research instruments deployed in a forest environment that incorporate multiple laser wavelengths to allow spectral dis-

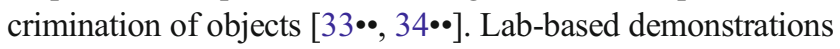
of the use of super continuum lasers have also demonstrated some potential for measuring the structure and spectral reflectance of vegetation [77]. The basis of a super continuum laser is the transmission of a broadband (white) laser pulse, such that the spectral intensity of the return pulse can be measured explicitly. Field testing of such an instrument in a forest environment is yet to be demonstrated.

Occlusion in TLS data is inherently incorporated into the gap probability approach. In geometrical modelling, occlusion generally needs to be overcome by merging scans recorded at multiple locations with a trade-off between sampling time and scan resolution/number. The efficiency and value of this approach would be increased if occlusion could be overcome in a way that is more efficient both in the field and during data processing. Mobile scanners provide one prospect for such an efficient measurement. Mobile scanners generally incorporate one or multiple single-axis scanners that are mounted on a vehicle, and a review of such systems is provided by Petrie and Toth [78]. While limited demonstration has been reported [79], the accessibility difficulties in forests for scanners mounted on a stable vehicle platform have limited their widespread use. An alternative to mobile scanning are handheld systems like the Zebedee [80॰], which uses automatic feature recognition to continually track the origin of the scanner. Bosse et al. [80 ] refer to this as simultaneous localisation and mapping (SLAM). The system has been tested in forest environments with some preliminary assessment of the results relative to conventional TLS [81].

\section{Methods Development}

Geometrical modelling at the plot scale requires survey control to achieve precise registration of scans over time and space. This can be inefficient relative to variable radius plot methods based on single scans, or multiple scans treated as independent samples, because it requires additional equipment, time and operator skill for plot establishment. Survey protocols that employ variable radius plots for input to $P_{\text {gap }}$ modelling methods will result in more rapid acquisition of plot data across large areas or more plots for the same investment [42].

A number of lidar and synthetic aperture radar (SAR) satellite missions designed for continental and global aboveground biomass mapping are scheduled for launch in the next 5 years. It is anticipated that a major driver for large-scale plot acquisition campaigns using TLS will be the calibration and validation of these satellite-based sensors for large-area aboveground biomass mapping [82]. Existing plot inventory data will not be sufficient, since it has been shown that a major source of difference between pan-tropical biomass maps is the result of inadequate ground data and allometrics for spatial extrapolation of satellite measurements [83]. Properties of medium spatial resolution satellite measurements such as sensor point spread function, adjacency effects and compositing of image products suggest that fixed area plots are less important than sampling designs that locate plots in contiguous heterogeneous stands of minimum sampling unit size (typically $1 \mathrm{ha}$ ). In addition to larger numbers of consistently measured plots, TLS-derived foliage profiles may be linked to airborne laser scanning (ALS) and unmanned air vehicle (UAV) lidar measurements of directional gap probability and then AGB as discussed previously. This provides a means of dramatically increasing the quantity of data available for spatial extrapolation of AGB from satellite measurements.

TLS-derived plant area and volume profiles provide a means not only to calculate integrated canopy metrics that are important for calibration and validation of satellite mapping and monitoring but also to partition these quantities between overstorey and understorey. This can be important for tracking the phenology and dynamics of complex forests, where the start of the growing season in the understorey may occur at a different time to the overstorey [84]. Modelling the profile $f(z)$ is also required for quantifying structural complexity as well as structural attributes in the context of biodiversity and habitat suitability assessment [85]. Method development in this area is presently focussed on separation of the leaf and woody area and volume components, so that $L(z)$ and related quantities may be estimated. This is widely useful and is likely to open up new uses of TLS in land management applications, such as examination of relationships between wood production, leaf recruitment and shedding, and water use in floodplain woodlands [86].

The need for separation of leaf and woody components is common to both geometric and $P_{\text {gap }}$ modelling of vegetation 
structure, dynamics and aboveground biomass. However, method development is still in the research phase, and results have been site and sensor specific. Côté et al. [66] and Béland et al. [87] have used discrete return apparent reflectance thresholds to separate leaf and woody components. Newnham et al. [88] used multiple discrete return intensity and textural attributes from a phase-shift ranging scanner. QSM-based approaches have used proximity of points from branching structure to filter out leaf returns $[68 \bullet \bullet, 69]$. All these approaches rely on indirect separation using statistical properties of the scans and are not yet applicable to multiple return scanners. As previously discussed, full-waveform scanners provide additional information on target properties and new dual-wavelength scanners such as SALCA and DWEL provide a direct way to separate scene components with spectral information, as well as account for partial beam interception based on return energy from full-waveform recording and processing [89].

It seems inevitable that operational plot surveys will transition to employing TLS, although plot-based vegetation monitoring initiatives and national forest inventories still require demonstration that the integrity of traditional structural metrics will be maintained. Geometric modelling may be the best solution to achieve this, because individual trees need to be identified and their structural form compared. Geometrical modelling may also be the key to detailed tree-level analyses such as tracking patterns of tree competition, growth and mortality in relation to changing temperature, rainfall and land use $[90,91]$. Plot-scale geometric modelling also presents an opportunity to develop new unconventional allometrics, particularly for aboveground biomass estimation. Any capacity to develop these equations without the need for destructive harvesting will significantly increase our understanding of error propagation to broad-scale mapping, particularly for trees in the largest size classes where the greatest uncertainty in relationships exists [92].

Existing optical and microwave canopy radiative transfer models often use extreme approximations of canopy structure to achieve rapid inversion or because detailed structural measurements are unavailable. We anticipate that realistic geometrically explicit plot-scale models based on TLS data will be used in place of simplified models based on traditional forest measurement for studies that model the canopy radiation regime such as Radiation Transfer Model Intercomparisons, RAMI $[93,94]$. Geometrically explicit models will allow the development of more realistic canopy scattering models for estimation of canopy properties from remote sensing data, to be used in optical and microwave radiative transfer modelling $[95,96]$. This prospect has led the European Space Agency and NASA to undertake TLS measurements of tropical forest plots in preparations for their forthcoming spaceborne BIOMASS SAR [97] and GEDI lidar [98] missions that aim to quantify tropical forest structure and biomass on regional to continental scales.
Advances in rapid geometric modelling at the plot scale are important if TLS is to move from research to an operational status. Initial investigations using the QSMs described previously have assumed constant parameters within a plot, showing that individual tree errors may cancel out when aggregated to the plot scale [99]. Plot-scale reconstructions with results of equivalent accuracy to the tree scale are yet to be demonstrated. There is potential that integration with lidar or photogrammetric 3D point clouds from UAV with multi-angular capabilities will improve geometric modelling of the upper canopy structure in closed forests, which are typically occluded from the ground-based perspective. These detailed 3D reconstructions may also be important in quantifying coarse woody debris and the horizontal and vertical continuity of foliage, thus improving estimates of fire hazard and biodiversity assessment. Fine-scale canopy components such as foliage and twigs dramatically increase the complexity of geometric modelling due their higher proportion of the total canopy area and volume. In future, geometrical modelling may be combined with gap probability approaches through voxelisation of multiple merged scans [100], so that individual plants or clumps are treated as geometric volumes in place of leaf and wood canopy elements [101].

In order for TLS to make the transition from a research to an operational tool, practical and cost-effective instruments, simple and efficient sampling protocols, widely available data processing software, and openly accessible data formats and distribution infrastructure need to be demonstrated [102]. Experimental comparison of varying instrument types and processing algorithms is required to increase our understanding of the roles, costs and accuracy trade-offs between approaches [103, 104]. Collaborative initiatives such the TLS International Interest Group (TLSIIG;tlsiig.bu.edu) can help to facilitate such comparisons, which are critical to develop of improved methods and hardware. Open access of TLS data and processing algorithms through national and international collaborative research programs and infrastructure will enable single-scan $P_{\text {gap }}$ statistical methods and multiple-scan geometric modelling techniques to be fully exploited and integrated to produce the most efficient and accurate plot-based forest structural information possible.

\section{Conclusions}

For over 10 years, researchers have been striving to develop methods that would allow TLS to replace manual plot-based survey methods, such as traditional forest inventory. This has not come to fruition because the strength of TLS is not in replicating measurements that can be easily done manually. The strength of this technology is in providing an assessment of structure that has not been achievable by any other means. It is still the case that the use of a diameter tape will generally be a cheaper, quicker and more accurate solution for determining 
mean plot DBH than a laser scanner. But, this is the extent of information that can be inferred from a diameter tape and only the start of the potential for TLS.

TLS is a transformational technology for plot-based forest surveys, not a logical extension of traditional manual methods. We only need to look at the information products derived from TLS to understand that these instruments measure and record a snapshot of forest resources in previously unthinkable detail. From the strata-specific density captured in foliage profiles to the detailed branching structure of geometrical models, the level of detail far surpasses any traditional inventory or ecological survey methods.

Fully exploiting the value of TLS requires a complete rethink of how structural information is used in forest biometrics, such as the assessment of merchantable volumes, biomass or habitat. Timber volume has already been shown to be directly accessible using detailed single tree modelling [58••]. Although the survey methods required to develop these models are more intensive, they present the perfect opportunity to investigate new unconventional isometric and allometric relationships, such as relationships between biomass and foliage profiles.

Plot-based surveys are not useful without some method to extrapolate the measurements to broader compartment, landscape or even national scales. In the case of TLS, this link can be made directly to airborne and spaceborne lidar instruments via vertically projected foliage profiles. This circumvents the need for scaling up using tenuous relationships between forest structure and spectral reflectance properties recorded by remote sensing systems, allowing more direct and physically based retrievals of canopy properties.

Just as Bitterlich [9•] revolutionised forest measurement in the mid-twentieth century with variable radius plots, TLS provides the opportunity to revolutionise plot measurement for the twenty-first century. The progress in hardware and modelling methods will only increase the scope of the impact of these instruments as we fully grasp how to properly utilise the rich forest structural information they provide.

Acknowledgments We would like to thank Dr. David Jupp for his ongoing contribution to TLS theory and methods. We would like to thank Dr. Michael Schaefer for supplying the figure showing the Normalised Difference Index derived from the DWEL scanner data.

\section{Compliance with Ethics Standards}

Conflict of Interest Dr. Newnham and Dr. Lovell's work has been previously supported by research grants from Forest and Wood Products Australia (FWPA).

Ongoing support for the development of TLS hardware and methods for forest measurement is being provided to Dr. Newnham and Dr. Armston by the Terrestrial Ecosystem Research Netowrk (TERN).

Dr. Calders has nothing to declare.

Dr. Disney wishes to acknowledge financial support from the NERC National Centre for Earth Observation (NCEO).

Dr. Schaaf, Dr. Strahler, Dr. Danson state that the US National Science Foundation has provided support for some co-authors under grants MRI0923389 and DBI-1455636.
Human and Animal Rights and Informed Consent This article contains no studies with human or animal subjects performed by the author.

\section{References}

Papers of particular interest, published recently, have been highlighted as:

- Of importance

•. Of major importance

1. Laar A Van, Akca A (2007) Forest mensuration. Springer Science \& Business Media

2. Walker J, Hopkins MS (1990) Vegetation, In Australian soil and land survey field handbook, 2nd ed. Inkata Press

3. Tomppo E, Gschwantner T, Lawrence M, et al. (2010) National Forest Inventories: Pathways for Common Reporting. European Science Foundation

4. Bechtold W, Patterson P. The enhanced forest inventory and analysis program: national sampling design and estimation procedures. Asheville: US Department of Agriculture Forest Service, Southern Research Station; 2005.

5. Turner J, Pribble J. Evaluation of Santiago Declaration (Montreal Process) indicators of sustainability for Australian commercial forests: a New South Wales alpine ash forest as a case study. State Forests of NSW: Research Division; 1996.

6. Oberthür S, Ott H (1999) The Kyoto Protocol: international climate policy for the 21 st century. Springer Science \& Business Media

7. Marthews T, Metcalfe D, Malhi Y, et al. (2012) Measuring tropical forest carbon allocation and cycling: A RAINFOR-GEM field manual for intensive census plots. Manual, Global Ecosystems Monitoring 2:

8. Jackson A. The Biltmore stick and its use on national forests. J For. 1911;9:406-11.

9. Bitterlich W. Die winkelzählprobe. Forstwissenschaftliches Centralblatt. 1952;71:215-25. The fundamental theory for measuring basal area using horizontal gap fraction estimates can be tracked back to the work of Bitterlich.

10. Sukwong S, Frayer W, Mogren E. Generalized comparisons of the precision fixed-radius and variable-radius plots for basal-area estimates. For Sci. 1971;17:263-71.

11. Grosenbaugh L. Plotless timber estimates - new, fast, easy. J For. 1952;50:32-7.

12. Whittaker R, Woodwell G (1968) Dimension and production relations of trees and shrubs in the Brookhaven Forest, New York. The Journal of Ecology 1-25.

13. Chave J, Réjou-Méchain M, Búrquez A, et al. Improved allometric models to estimate the aboveground biomass of tropical trees. Glob Chang Biol. 2014;20:3177-90.

14. Williams R, Zerihun A, Montagu K, et al. Allometry for estimating aboveground tree biomass in tropical and subtropical eucalypt woodlands: towards general predictive equations. Aust J Bot. 2005;53:607-91.

15. Bréda NJJ. Ground-based measurements of leaf area index: a review of methods, instruments and current controversies. J Exp Bot. 2003;54:2403-17.

16.• MacArthur R, Horn H (1969) Foliage profile by vertical measurements. Ecology 802-804. Although the measurement of leaf area and light interception predates this paper, this work decribes the 
theory for measuring foliage profiles (leaf area as a function of height), which is now applied in TLS based assessment of forests.

17. Clutter J (1957) The effect of stand conditions and angle size on plotless cruising basal area estimates in loblolly pine... Duke University

18. Husch B. Results of an investigation of the variable plot method of cruising. J For. 1955;53:570-4.

19.•• Lovell JL, Jupp DLB, Culvenor DS, Coops NC. Using airborne and ground-based ranging lidar to measure canopy structure in Australian forests. Can J Remote Sens. 2003;29:607-22. This provides a very clear and comprehensive summary of methods for estimating foliage profiles from both TLS and ALS data.

20. Hopkinson C, Chasmer L, Young-Pow C, Treitz P. Assessing forest metrics with a ground-based scanning lidar. Can J For Res. 2004;34:573-83.

21. Pfeifer N, Briese C. Laser scanning - principles and applications. Institute of Photogrametry and Remote Sensing: Vienna University of Technology; 2007.

22. Nelson R, Krabill W, MacLean G. Determining forest canopy characteristics using airborne laser data. Remote Sens Environ. 1984;15:201-12.

23. Ullrich A, Reichert R, Studnicka N, Riegl J. High-performance 3D-imaging laser sensor. In: EUROPTO Conference on Laser Radar Technology and Applications. Munich, Germany; 1999. p. $658-64$.

24. Kacyra B, Dimsdale J, Brunkhart M. Integrated system for quickly and accurately imaging and modeling three dimensional objects. US Patent. 1999;5:988,862.

25. Jutzi B, Stilla U. Measuring and processing the waveform of laser pulses. Optical. 2005;3:194-203. Clearly describes how continuous intensity returns can be converted into discrete ranges, thus linking full waveform and discrete TLS technologies.

26. Fröhlich $\mathrm{C}$, Mettenleiter $\mathrm{M}$. Terrestrial laser scanning - new perspectives in 3D surveying. Int archives photogrammetry, remote sensing spatial information sci. 2004;36:W2.

27. Salo P, Jokinen O, Kukko A. On the calibration of the distance measuring component of a terrestrial laser scanner. Proc XXIth ISPRS Congress. 2008;37:B5.

28.• Strahler AH, Jupp DLB, Woodcock CE, et al. Retrieval of forest structural parameters using a ground-based lidar instrument ( Echidna $\left.{ }^{\circledR}\right)$ ). Can J Remote Sens. 2008;34:S426-40. Describes the use of gap fraction for characterising both the leafy (foliage profiles) and woody components (stem diameters and basal area) of forests.

29.• Jupp DLB, Culvenor DS, Lovell JL, et al. Estimating forest LAI profiles and structural parameters using a ground-based laser called 'Echidna. Tree Physiol. 2009;29:171-81. Describes a linear method for estimation of both foliage area volume density and the projection function (Ross $\mathrm{G}$ function).

30. Weitkamp C (2006) Lidar: range-resolved optical remote sensing of the atmosphere. Springer

31. Measures RM (1992) Laser remote sensing: fundamentals and applications. Krieger

32. Gaulton R, Danson FM, Pearson G, et al. The Salford Advanced Laser Canopy Analyser (SALCA): a multispectral full waveform LiDAR for improved vegetation characterisation. Proceedings of the Remote Sensing and Photogrammetry Society Conference. London: Remote Sensing and the Carbon Cycle; 2010

33.• Danson FM, Gaulton R, Armitage RP, et al. Developing a dualwavelength full-waveform terrestrial laser scanner to characterize forest canopy structure. Agric For Meteorol. 2014;198-199:7-14. Introduces the use of dual-waveform scanning for forest measurement

34.• Douglas ES, Martel J, Li Z, et al. Finding leaves in the forest: the dual-wavelength Echidna lidar. IEEE Geosci Remote Sens Lett.
2015;12:776-80. Provides an engineering focussed description of the DWEL dual-waveform TLS system.

35. Gaulton R, Danson FM, Ramirez FA, Gunawan O. The potential of dual-wavelength laser scanning for estimating vegetation moisture content. Remote Sens Environ. 2013;132:32-9.

36. Monsi M, Saeki T. On the factor light in plant communities and its importance for matter production. 1953. Ann Bot. 2005;95:549 67.

37. Ross I. The radiation regime and architecture of plant stands. The Hague: Junk Publishers; 1981.

38. Campbell G. Extinction coefficients for radiation in plant canopies calculated using an ellipsoidal inclination angle distribution. Agric For Meteorol. 1986;36:317-21.

39. Welles J, Cohen S. Canopy structure measurement by gap fraction analysis using commercial instrumentation. J Exp Bot. 1996;47: 1335-42.

40. Radtke P, Bolstad P. Laser point-quadrat sampling for estimating foliage-height profiles in broad-leaved forests. Can J For Res. 2001;31:410-8.

41. Zhao F, Strahler A, Schaaf C, Yao T. Measuring gap fraction, element clumping index and LAI in Sierra Forest stands using a full-waveform ground-based lidar. Remote Sens Environ. 2012;125:73-9.

42. Calders K, Armston J, Newnham G, et al. Implications of sensor configuration and topography on vertical plant profiles derived from terrestrial LiDAR. Agric For Meteorol. 2014;194:104-17.

43. Pueschel P, Newnham G, Hill J. Retrieval of gap fraction and effective plant area index from phase-shift terrestrial laser scans. Remote Sens. 2014;6:2601-27.

44. Lovell JL, Jupp DLB, Newnham GJ, Culvenor DS. Measuring tree stem diameters using intensity profiles from ground-based scanning lidar from a fixed viewpoint. ISPRS J Photogramm Remote Sens. 2011;66:46-55.

45. Yao T, Yang X, Zhao F, et al. Measuring forest structure and biomass in New England forest stands using Echidna groundbased lidar. Remote Sens Environ. 2011;115:2965-74.

46. Van Leeuwen M, Hilker T, Coops NC, et al. Assessment of standing wood and fiber quality using ground and airborne laser scanning: a review. For Ecol Manag. 2011;261:1467-78.

47. Zhao F, Yang X, Strahler A, Schaaf C. A comparison of foliage profiles in the Sierra National Forest obtained with a fullwaveform under-canopy EVI lidar system with the foliage profiles obtained with an airborne full-waveform LVIS lidar system. Remote Sens Environ. 2013;136:330-41.

48. Jupp D. Ground based and airborne lidar - a natural combination. Australia: Silvilaser 2011, Hobart; 2011. Highlights the natural synergy between TLS and ALS that is yet to be fully exploited.

49. Aschoff T, Spiecker H. Algorithms for the automatic detection of trees in laser scanner data. Int Archives Photogrammetry, Remote Sensing Spatial Informat Sci. 2004;36:W2.

50. Bienert A, Scheller S, Keane E, et al. (2007) Tree detection and diameter estimations by analysis of forest terrestrial laserscanner point clouds. In: ISPRS workshop on laser scanning. pp 50-55

51. Tansey K, Selmes N, Anstee A, et al. Estimating tree and stand variables in a Corsican Pine woodland from terrestrial laser scanner data. Int J Remote Sens. 2009;30:5195-209.

52. Pfeifer N, Winterhalder D. Modelling of tree cross sections from terrestrial laser scanning data with free-form curves. Int Archives Photogrammetry, Remote Sensing Spatial Informat Sci. 2004;36: W2.

53. Pfeifer N, Gorte B, Winterhalder D, et al. (2004) Automatic Reconstruction of Single Trees From Terrestrial Laser Scanner Data. In: Proceedings of 20th ISPRS Congress. Citeseer, pp 114-119

54. Bienert A, Scheller S, Keane E, Mullooly G, Mohan F. Application of terrestrial laser scanners for the determination of 
forest inventory parameters. Int Arch Photogramm Remote Sens Spat Inf Sci. 2006;36. no. Part 5.

55. Pueschel P, Newnham G, Rock G, et al. The influence of scan mode and circle fitting on tree stem detection, stem diameter and volume extraction from terrestrial laser scans. ISPRS J Photogramm Remote Sens. 2013;77:44-56.

56. Hilker T, Coops N. A simple technique for co-registration of terrestrial LiDAR observations for forestry applications. Remote Sensing Letters. 2012;3:239-47.

57. Seidel D, Fleck S, Leuschner C. Analyzing forest canopies with ground-based laser scanning: a comparison with hemispherical photography. Agric For Meteorol. 2012;154-155:1-8.

58.• Calders K, Newnham G, Burt A, et al. Nondestructive estimates of above-ground biomass using terrestrial laser scanning. Methods Ecol Evol. 2015;6:198-208. To date this is the most encouraging results from TLS for measurement of forest biomass.

59. Hancock S, Essery R, Reid T, et al. Characterising forest gap fraction with terrestrial lidar and photography: an examination of relative limitations. Agric For Meteorol. 2014;189-190:105-14.

60. Henning J, Radtke P. Detailed stem measurements of standing trees from ground-based scanning lidar. For Sci. 2006;52:67-80.

61. Burt A, Disney MI, Raumonen P, et al. (2013) Rapid characterisation of forest structure from TLS and 3D modelling. In: 2013 I.E. International Geoscience and Remote Sensing Symposium - IGARSS. IEEE, pp 3387-3390

62. Yang X, Strahler A, Schaaf C. Three-dimensional forest reconstruction and structural parameter retrievals using a terrestrial full-waveform lidar instrument $\left(\right.$ Echidna $\left.{ }^{\circledR}\right)$. Remote Sens Environ. 2013;135:36-51.

63. Hosoi F, Nakai Y, Omasa K. 3-D voxel-based solid modeling of a broad-leaved tree for accurate volume estimation using portable scanning lidar. ISPRS J Photogramm Remote Sens. 2013;82:418.

64. Béland M, Widlowski J-L, Fournier RA, et al. Estimating leaf area distribution in savanna trees from terrestrial LiDAR measurements. Agric For Meteorol. 2011;151:1252-66.

65. Dassot M, Colin A, Santenoise P, et al. Terrestrial laser scanning for measuring the solid wood volume, including branches, of adult standing trees in the forest environment. Comput Electron Agric. 2012;89:86-93

66. Côté J, Widlowski J. The structural and radiative consistency of three-dimensional tree reconstructions from terrestrial lidar. Remote Sens Environ. 2009;113:1067-81.

67. Côté J-F, Fournier RA, Egli R. An architectural model of trees to estimate forest structural attributes using terrestrial LiDAR. Environ Model Softw. 2011;26:761-77.

68.• Raumonen P, Kaasalainen M, Åkerblom M, et al. Fast automatic precision tree models from terrestrial laser scanner data. Remote Sens. 2013;5:491-520. Three dimensional tree modelling algorithm that has been adopted by a number of other authors for assessing tree form, volume and biomass.

69. Hackenberg J, Morhart C, Sheppard J, et al. Highly accurate tree models derived from terrestrial laser scan data: a method description. Forests. 2014;5:1069-105.

70. Liski J, Kaasalainen S. Indirect emissions of forest bioenergy: detailed modeling of stump-root systems. Glob Chang Biol. 2014;6:777-84

71. Kelbe D, Romanczyk P, van Aardt J, et al. Automatic extraction of tree stem models from single terrestrial lidar scans in structurally heterogeneous forest environments. In: 12th International conference on LiDAR applications for assessing forest ecosystems. Canada: SilviLaser 2012. Vancouver; 2012. p. 16-9.

72. Schaaf C, Paynter I, Saenz EJ, et al. Using the Rapid-Scanning, Ultra-Portable, Canopy Biomass Lidar (CBL) Alone and In Tandem with the Full-Waveform Dual-Wavelength Echidna ${ }^{\circledR}$ Lidar (DWEL) to Establish Forest Structure and Biomass
Estimates in a Variety of Ecosystems. Am Geophysical Union Fall Meet Abstracts. 2014;1:1.

73. Schaaf C, Paynter I, Saenz E, et al. Canopy biomass lidar (CBL) acquisitions at NEON and TERN forest sites. Am Geophysical Union Fall Meet Abstracts. 2013;1:449.

74. Eitel JUH, Vierling LA, Magney TS. A lightweight, low cost autonomously operating terrestrial laser scanner for quantifying and monitoring ecosystem structural dynamics. Agric For Meteorol. 2013;180:86-96.

75. Culvenor DS, Newnham GJ, Mellor A, et al. Automated in-situ laser scanner for monitoring forest leaf area index. Sensors (Basel, Switzerland). 2014;14:14994-5008.

76. Griebel A, Bennett LT, Culvenor DS, et al. Reliability and limitations of a novel terrestrial laser scanner for daily monitoring of forest canopy dynamics. Remote Sens Environ. 2015;166:205-13. Details of a permanently mounted TLS system and an example of the growing diversity of TLS systems for forest measurement.

77. Hakala T, Suomalainen J, Kaasalainen S, Chen Y. Full waveform hyperspectral LiDAR for terrestrial laser scanning. Opt Express. 2012;20:7119-27.

78. Petrie G, Toth C (2009) Terrestrial laser scanners. In: Topographic Laser Ranging and Scanning Principles and Processing. pp 87128

79. Liang X, Hyyppa J, Kukko A, et al. The use of a mobile laser scanning system for mapping large forest plots. IEEE Geosci Remote Sens Lett. 2014;11:1504-8.

80. Bosse M, Zlot R, Flick P. Zebedee: design of a spring-mounted 3-d range sensor with application to mobile mapping. Robotics. IEEE Trans Robot. 2012;28:1104-19. Details of a mobile TLS system which has found application for forest measurement.

81. Ryding J, Williams E, Smith M, Eichhorn M. Assessing handheld mobile laser scanners for forest surveys. Remote Sens. 2015;7: 1095-111.

82. Lucas RM, Mitchell AL, Armston J (2015) Measurement of forest above ground biomass using active and passive remote sensing at large (country and continental) scales. Forestry Reports (in review)

83. Mitchard E, Saatchi S, Baccini A, et al. Uncertainty in the spatial distribution of tropical forest biomass: a comparison of pantropical maps. Carbon bal management. 2013;8:1-13.

84. Calders K, Schenkels T, Bartholomeus H, et al. Monitoring spring phenology with high temporal resolution terrestrial LiDAR measurements. Agric For Meteorol. 2015;203:158-68.

85. Yang X, Schaaf C, Strahler A, et al. Study of bat flight behavior by combining thermal image analysis with a LiDAR forest reconstruction. Can J Remote Sens. 2014;39:S112-25.

86. Holloway D, Biggs A, Marshall J, McGregor G (2013) Watering requirements of floodplain vegetation asset species of the Lower Balonne River Floodplain: Review of scientific understanding and identification of knowledge gaps for asset species of the northern Murray-Darling Basin. Brisbane

87. Béland M, Baldocchi DD, Widlowski J-L, et al. On seeing the wood from the leaves and the role of voxel size in determining leaf area distribution of forests with terrestrial LiDAR. Agric For Meteorol. 2014;184:82-97.

88. Newnham G, Mashford J, Püschel P, et al. Non-parametric point classification for phase-shift laser scanning. Canada: SilviLaser 2012 Vancouver; 2012.

89. Li Z, Strahler AH, Schaaf C, et al. Separating leaves from trunks and branches with dual-wavelength terrestrial lidar scanning: improving canopy structure characterization in 3-D space. Am Geophys Union. 2013;1:0289.

90. Prior LD, Bowman DMJS. Big eucalypts grow more slowly in a warm climate: evidence of an interaction between tree size and temperature. Glob Chang Biol. 2014;20:2793-9. 
91. Burrows WH, Henry BK, Back PV, et al. Growth and carbon stock change in eucalypt woodlands in northeast Australia: ecological and greenhouse sink implications. Glob Chang Biol. 2002;8:76984.

92. Chave J, Andalo C, Brown S, et al. Tree allometry and improved estimation of carbon stocks and balance in tropical forests. Oecologia. 2005;145:87-99.

93. Van Leeuwen M, Coops NC, Hilker T, et al. Automated reconstruction of tree and canopy structure for modeling the internal canopy radiation regime. Remote Sens Environ. 2013;136:286300.

94. Widlowski J-L, Pinty B, Lopatka M, et al. The fourth radiation transfer model intercomparison (RAMI-IV): proficiency testing of canopy reflectance models with ISO-13528. J Geophysical Res: Atmospheres. 2013;118:6869-90.

95. Disney MI, Lewis P, Gomez-Dans J, et al. 3D radiative transfer modelling of fire impacts on a two-layer savanna system. Remote Sens Environ. 2011;115:1866-81.

96. Disney M, Lewis P, Saich P. 3D modelling of forest canopy structure for remote sensing simulations in the optical and microwave domains. Remote Sens Environ. 2006;100:114-32.

97. Le Toan T, Quegan S, Davidson MWJ, et al. The BIOMASS mission: smapping global forest biomass to better understand the terrestrial carbon cycle. Remote Sens Environ. 2011;115:285060 .
98. Dubayah R, Goetz S, Blair JB, et al. The Global Ecosystem Dynamics Investigation (GEDI) Lidar. Italy: ForestSAT Conference 2014, Riva del Garda; 2014.

99. Raumonen P, Casella E, Calders K, et al. Massive-scale tree modelling from TLS data. ISPRS Annals of the Photogrammetry. Remote Sensing Spatial Informat Sci. 2015;II3(W4):189-96.

100. Strahler AH, Yang X, Li Z, et al. (2013) Retrieving Leaf Area Index and Foliage Profiles Through Voxelized 3-D Forest Reconstruction Using Terrestrial Full-Waveform and DualWavelength Echidna Lidars. In: AGU Fall Meeting. p 0290

101. Greaves HE, Vierling LA, Eitel JUH, et al. Estimating aboveground biomass and leaf area of low-stature Arctic shrubs with terrestrial LiDAR. Remote Sens Environ. 2015;164:26-35.

102. Bunting P, Armston J, Lucas RM, Clewley D. Sorted pulse data (SPD) library. Part I: A generic file format for LiDAR data from pulsed laser systems in terrestrial environments. Comp Geosci. 2013;56:197-206.

103. Newnham G, Armston J, Muir J, et al. Evaluation of terrestrial laser scanners for measuring vegetation structure. Australia: CSIRO; 2012.

104. Armston J, Newnham G, Strahler A, et al. A Comparison of Terrestrial Laser Scanning Instruments for Assessing Forested Ecosystems. Italy: ForestSAT2014, Riva del Garda; 2014. 